NBER WORKING PAPER SERIES

EQUILIBRIUM POLITICAL BUDGET CYCLES

Kenneth Rogoff

Working Paper No. 2428

NATIONAL BUREAU OF ECONOMIC RESEARCH

1050 Massachusetts Avenue

Cambridge, MA 02138

November 1987

Support from the Lynde and Harry Bradley Foundation is gratefully acknowledged. The research reported here is part of the NBER's research program in Financial Markets and Monetary Economics. Any opinions expressed are those of the author and not those of the National Bureau of Economic Research. 


\section{Equilibrium Political Budget Cycles}

\section{ABSTRACT}

Prior to elections, governments (at all levels) frequentiy undertake a consumption binge. Taxes are cut, transfers are raised, and government spending is distorted towards highly visible items. The "political business cycle" (better be thought of as "the political budget cycle") has been intensively examined, at least for the case of national elections. A number of proposals have been advanced for mitigating electoral cycles in fiscal policy. The present paper is the first effort to provide a fully-specified equilibrium framework for analyzing such proposals. A political budget cycle arises here via a multidimensional signalling process, in which incumbent leaders try to convince voters that they have recently been doing an excellent job in administering the government. Efforts to mitigate the cycle can easily prove counterproductive, either by impeding the transmission of information or by inducing politicians to select more costly ways of signalling. The model also indicates new directions for empirical research.

\author{
Kenneth Rogoff \\ Economics Department \\ 1180 Observatory Orive \\ University of Wisconsin \\ Madison, WI 53706
}

(608)-263-3876 


\section{Introduction}

Economists and political scientists have tried for some time to understand the apparent coincidence of macroeconomic policy cycles and elections. But although researchers have detected some notable empirical regularities ${ }^{1}$ (particularly concerning pre-election tax cuts and government spending increases), progress has been impeded by the lack of a solid theoretical foundation. The present paper is an effort to remedy this situation.

My analysis is based on an intertemporal equilibrium model in which both voters and politicians are rational, utility-maximizing agents. ${ }^{2}$ A "political budget cycle" arises due to temporary information asymmetries about the incumbent leader's competence in administering the production of public goods. Equilibrium is characterized by a multidimensional signalling process. The model is useful in part because it delivers sharp empirical predictions concerning the timing of budget cycles and elections, and the nature of the induced fiscal distortions. Prior to elections, taxes tend to be suboptimally low and government consumption spending suboptimally high. This public and private consumption binge comes at the expense of government investment.

The model also provides a welfare-theoretic framework for analyzing various reforms aimed at alleviating the political budget cycle. ${ }^{3}$ One can explicitly analyze the effects of balanced-budget amendments and of constitutional limits on the legislature's ability to undertake new tax and expenditure initiatives directly prior to elections. I also consider the effects of increasing central bank independence and of trying to channel pre-election signalling into campaign expenditures. Fairly direct extensions of the model can be applied to analyze changes in the length of politicians' terms 
in office, and the adoption of more sophisticated rules for governing the timing of elections.

The popular perception is that political budget cycles are a bad thing. But a central conclusion of this analysis is that the pre-election budget antics of incumbent politicians may be a socially efficient mechanism for diffusing up-to-date information about their competence. Efforts to mitigate the political budget cycle can easily reduce welfare, either by impeding the transmission of information or by inducing politicians to select more costly (to society) ways of signalling. 4

In section II, I present the model, including the constitutionally-imposed election structure. Section III gives the equilibrium under full information, and sections IV - VI characterize the fiscal policy distortions which occur under asymmetric information. There are multiple sequential equilibria but, following Milgrom and Roberts (1986), I apply some refinements of sequential equilibrium to obtain a unique equilibrium. In section VII I critically assess some proposed reforms of the political budget cycle process.

\section{The Model}

\section{A. The Preferences of a Representative Agent}

The economy is composed of a large number of (ex-ante identical) agents, each of whom derives utility both from public goods and from a private consumption good. The representative voter $i$ is concerned with his expected utility:

$$
\begin{aligned}
& \varphi_{t}^{i}=\varepsilon_{t}^{i}\left(\Gamma_{t}^{i}+\sum_{s=t}^{T} x_{t}^{i} \beta^{s-t}\right), \\
& \Gamma_{t}^{i}=\sum_{s=t}^{T}\left[U\left(c_{s}^{i}, g_{s}\right)+v\left(k_{s}\right)+\eta_{s}\right] \beta^{s-t},
\end{aligned}
$$


where $c^{i}$ is the agent's consumption of the private good, $g$ is the public "consumption" good, and $k$ is the public "investment" good. $U$ and $V$ are both regular strictly concave functions, with $U_{1}, U_{2}, V^{\prime}>0$. In addition to assuming the usual Inada conditions, I make the further assumption that $\lim _{k \rightarrow 0} V(k)=-\infty[e . g ., V(k)=\log k]$. The latter assumption is sufficient to $k \rightarrow 0$ insure an interior solution in the asymmetric information case. $\beta<1$ is the representative agent's discount factor, $E^{i}$ is the expectations operator (conditional on agent i's information set), $t$ subscripts denote time, and $T$ is the agent's time horizon which may be infinite. $\eta$ is a random shock, which will later be identified with nonpecuniary leader-specific factors such as the leader's looks. Finally, $x^{i}=0$ if agent $i$ is a private citizen in period $s$, and $x^{i}=x$ if agent $i$ is the country's leader in period $s . x$ represent's nonpecuniary ego rents which accrue to the country's leader. I discuss both $\eta$ and $x$ in more detail below.

\section{B. Technology}

At the beginning of each period, all agents exogenously receive $\bar{y}$ units of a nonstorable good, which can either be privately consumed or used as an input into the production of public goods. Out of this endowment, agents must pay $\tau_{t}$ in lump-sum taxes; they consume the remainder.

The technology for providing public goods is such that exactly one agent (a "leader") is needed to supervise production; output goes to zero if more supervisors are added. The production function for $g$ and $k$ is $g$ iven by 5

$$
g_{t}+k_{t+1}=\tau_{t}+\epsilon_{t}
$$

(Both $g$ and $k$ are measured in per capita units; population is constant throughout.) The relative cost of producing $g$ and $k$ is unity, but to have the 
public "investment good" $k$ in period $t+1$, the government must invest in period $t$. $g$ is nonstorable, and the stock of $k_{t+1}$ melts at the end of period $t+1$. There are two variable inputs into the public goods production process: taxes, $\tau$, and the leader's administrative competency, $\epsilon$. A competent administrator (high $\epsilon$ ) is able to provide a given level of public goods at a lower level of taxes than an incompetent administrator can. Competency is not a choice variable for the leader, but an individual characteristic. $\epsilon$ should be thought of as administrative IQ.

\section{Stochastic Structure}

A11 agents are capable of serving as the leader. However, at any given point in time, they differ according to their administrative competency. For each agent $i$, competency evolves according to the serially-correlated stochastic process

$$
\epsilon_{t}^{i}=a_{t}^{i}+a_{t-1}^{i}
$$

where each $\alpha^{i}$ is an independent drawing from a Bernoulli distribution with $\rho \equiv \operatorname{prob}\left(\alpha^{i}=\alpha^{H}\right)$, and $1-\rho \equiv \operatorname{prob}\left(\alpha^{i}=\alpha^{L}\right), \alpha^{H}>\alpha^{L}>-\bar{y} / 2$. The $\alpha$ shocks are independent across agents as we 11 as across time. One reason why competency might realistically be thought to vary over time is that leadership abilities well-suited to dealing with one set of historical circumstances may be poorly suited to dealing with other types of problems. Also, in a more general mode1, a leader's competency may change as his subordinates turn over. The restriction that $\epsilon$ follow a first-order moving average [MA(1)] process will turn out to simplify the analysis below considerably, as it effectively breaks structural links between elections. However, the analys is can be extended to allow for more general stochastic processes along the lines of Terrones (1987). 
In addition to the competency shock, each agent $i$ experiences a "looks" shock $\eta$, which also follows on MA(1) process:

$$
\eta_{t}^{i}=q_{t}^{i}+q_{t-1}^{i}
$$

where $q^{i}$ is a continuously distributed $i . i . d$. random variable on $[-\bar{q}, \bar{q}]$. $q_{t}^{i}$ and $q_{s}^{j}$ are independent for $a 11 s \neq t, i \neq j$. In what follows, it is the probability distribution of $\Delta q^{i j}=q^{i}-q^{j}, i \neq j$, which matters for all the results. I assume that $\Delta q^{i j}$ has probability distribution function $G(\Delta q)$; it has mean zero. $\eta$ is intended to capture factors relevant to an agent's leadership ability but uncorrelated with his competence in administering the public goods production function; e.g., his "looks". Neither $\epsilon^{i}$ nor $\eta^{i}$ matter for anything when agent $i$ is a private citizen. In eqs. (1) and (2) and in what fol lows below, whenever $\epsilon, \eta, a$ or $q$ are written without a superscript, they refer to the incumbent.

\section{The Structure of Elections}

In order to determine which agent gets the honor of administering the production of public goods, the country's constitution specifies that elections be held every other period. The incumbent leader is allowed to run for re-election an indefinite number of times, ${ }^{6}$ whereas the opposition candidate is chosen at random from the rest of the population. ${ }^{7}$ Under the information structure specified below, the essential difference between the incumbent leader and his opponent is going to be that the public can infer something about the incumbent's most recent competency shock, but it has no way of inferring anything about his opponent's competency. For voters, the choice is essentially between re-electing the incumbent or selecting an agent from 
the population-at-large, all of whom appear identical ex ante.

\section{E. The Leader's Utility Function}

All agents, including the country's leader, share the same utility function (1). Recall that the only difference is that $x^{i}=0$ during periods agent $i$ is a private citizen, and $x^{i}=x$ during periods he is the leader. As leader, an agent enjoys "ego rents". (There is no way to have public goods produced without yielding ego rents as a byproduct of the production process). Although the typical citizen would like someday to be the leader, unfortunately for $\operatorname{him} E_{t}^{i}\left(x_{s}^{i}\right)=0 \forall s \geqslant t$, and $\forall i \neq j$, with $j$ denoting the country's leader. There are a very large number of agents, and so a private citizen attaches infinitesimal value to his chances of ever becoming leader. Thus for a representative private citizen, the utility function (1) effectively reduces to

$$
\varphi_{t}^{P}=E_{t}^{P}\left(\Gamma_{t}^{P}\right)
$$

where "P" superscripts denote the "public". An incumbent politician, on the other hand, has a finite probability $\pi_{s}$ of being in office in period $s ; \pi_{s}$ will be derived later on. Using this notation, the leader's utility function is given by ${ }^{8}$

$$
\Phi_{t}^{I}=E_{t}^{I}\left(\Gamma_{t}^{P}\right)+\sum_{s=t}^{T} X \pi_{s} \beta^{s-t} .
$$

In the present model. I assume that a leader's motivations are entirely selfish. But it should be clear from inspection of eq. (6) that all of the (positive) results below would be the same under a more "generous" assumption Specifically, one can interpret eq. (6) as saying that the leader puts some weight on social welfare, $\Gamma_{t^{\prime}}^{P}$ and some weight on the rents he gets from 
being in office. (The model is also readily extended to the case where the leader's rents depend on his plurality).

\section{F. The Information Structure and the Timing of Events}

Voters observe taxes $\tau$ and government consumption spending $g$ contemporaneously. They also form inferences concerning government investment spending $k$ and the incumbent's competency shock $\alpha$, but they cannot directly confirm these inferences until the following period. In period $t+1$, the government's period $t$ investment comes on line ${ }^{9}$; voters also see $a_{t}$ directly in $t+1$.

The incumbent has a temporary information "advantage" over voters in that he sees his competency shock immediately. I use "advantage" in quotation marks because in fact, it will turn out that voters can use $g_{t}$ and $\tau_{t}$ to infer $\alpha_{t}$, and their inferences are always correct in equilibrium. The information structure assumed here seems plausible since it would be costly for an individual to closely monitor the government's performance. Moreover, there is little private incentive for an individual to undertake such monitoring since, in equilibrium, he can infer $\alpha_{t}$ costlessly using his information on $g_{t}$ and $\tau_{t}$. Government consumption spending and taxes are variables which individuals need to know and realistically can observe quite easily. Of course, if some group were able to monitor the government, and credibly transmit that information to individuals in a way which would be costless for them to process, that would preclude a political budget cycle in the analysis below. Clearly, neither the opposition candidate nor the incumbent can provide this service, since their statements cannot be trusted. The results below should go through in a more general setting in which some voters monitor $\alpha_{t^{\prime}}$ as long as there is a pool of "uniformed" voters who infer $\alpha_{t}$ instead. 
The public, of course, has no way of inferring $\alpha_{t}^{0}$, where "o" superscripts denote the opponent. (The opponent has no way of knowing $\alpha^{0}$ either, until he actually tries his hand at running the government.) All voters know about the opponent's competency is the probability distribution of $\alpha$. Prior to voting. voters do observe both $q_{t}$ and $q_{t}^{0}$, the "looks" shocks.

The incumbent sets $g$ and $\tau$ prior to observing the $q$ 's. The rationale for this assumption is that it takes time to collect taxes and to operate the government production function. The q shocks, on the other hand, capture information revealed in the election-eve debates or uncertainty about a lastminute scandal concerning one of the candidates. In an alternative version of the model, q might represent uncertainty about election-day weather, and hence about the composition of voters who come to the polls. Table 1 presents the timing of events.

In deciding his vote, the representative voter compares his expected utility under each of the two candidates. If $v=1$ denotes a vote for the incumbent, and $v=0$ a vote for his opponent, then

$$
u_{t}= \begin{cases}1 & \text { if } \varepsilon_{t}^{P}\left(\Gamma_{t+1}^{P}\right) \geqslant \varepsilon_{t}^{P}\left(\Gamma_{t+1}^{P}\right)^{0} \\ 0, \text { otherwise. }\end{cases}
$$

\section{Equilibrium Under Full Information}

Before proceeding, it is useful to analyze the equilibrium which would arise if voters could directly observe $a_{t}$ prior to voting. In this case, the incumbent's pre-election fiscal policy cannot possibly affect voters' expectations about his post-election competency, and thus can have no effect on his chances of remaining in office. With the $\pi$ terms in (6) exogenous, the incumbent's decision problem becomes equivalent to maximizing the welfare of the representative agent, $\Gamma^{P}$. Given the simple production and storage tech- 
nology, this intertemporal maximization problem can be broken down into a sequence of static maximization problems:

(8)

$$
\tau_{t}, c_{t}, g_{t}, k_{t+1} U\left(c_{t}, g_{t}\right)+\beta V\left(k_{t+1}\right), \quad \forall t
$$

subject to (2) and

$$
c_{t}=\bar{y}-\tau_{t}
$$

$$
k_{t+1}, g_{t} \geqslant 0
$$

Equation (9) is a private agent's budget constraint. Note that $\tau$ is allowed to take on negative values (there can be transfers as well as taxes). ${ }^{10}$

It is convenient to rewrite the above maximization problem by substituting the constraints (2) and (9) into (8) and (10):

$$
\begin{aligned}
& \max _{\tau, g} W(g, \tau, \epsilon)=U(\bar{y}-\tau, g)+\beta V(\tau+\epsilon-g) \\
& \text { s.t. } g_{t} \geqslant 0, \tau+\epsilon-g \geqslant 0 .
\end{aligned}
$$

(t subscripts will henceforth be omitted where the meaning is obvious.) The first-order conditions for an interior solution to (11) imply

$$
U_{1}(\bar{y}-\tau, g)=U_{2}(\bar{y}-\tau, g)=\beta V^{\prime}(\tau+\epsilon-g) .
$$

That the solution must be interior follows from the Inada conditions on $U$ and $V$. It is readily confirmed that there is a unique $\left[g^{\star}(\epsilon), T^{\star}(\epsilon)\right]$ which satisfies (12), and that this point is a global maximum. ${ }^{11}$ clearly

$$
W *(\epsilon) \geq W *\left[g^{\star}(\epsilon), T^{\star}(\epsilon), \epsilon\right]
$$


is strictly increasing in $\epsilon$ and, if all goods are normal, then $c^{\star}(\epsilon), g^{\star}(\epsilon)$ and $k^{\star}(\epsilon)$ are also increasing in $\epsilon$. Then by $(9), \tau^{\star}(\epsilon)$ must be decreasing. If $t$ is an election period, then by eqs. (3), (4), (5), (7) and (11), the incumbent will be re-elected $(v=1)$ if

$$
E_{t}^{P}\left[W *\left(\epsilon_{t+1}\right)\right]-E_{t}^{P}\left[W *\left(\epsilon_{t+1}^{0}\right]+q_{t}-q_{t}^{0} \geqslant 0 .\right.
$$

Because $\epsilon$ and $\eta$ follow MA(1) processes, voters' expected utility is the same under either candidate for periods $t+2$ and beyond, and thus only expectations over $t+1$ enter into (13). (Recall from Table 1 that voters observe $q_{t}$ and $q_{t}^{0}$ prior to the election.)

If voters observe $a_{t}=a^{H}$ prior to voting, then the first term in eq. (13) is given by

$$
E_{t}^{P}\left[W *\left(\epsilon_{t+1}\right) \mid \alpha_{t}=\alpha^{H}\right]=\Omega^{H}=\rho W *\left(2 \alpha^{H}\right)+(1-\rho) W *\left(\alpha^{H}+\alpha^{L}\right) .
$$

If voters instead observe $a_{t}=a^{L}$, then

$$
E_{t}^{P}\left[W *\left(\epsilon_{t+1}\right) \mid \alpha_{t}=\alpha^{L}\right] \equiv \Omega^{L}=\rho W *\left(\alpha^{H}+\alpha^{L}\right)+(1-\rho) W *\left(2 \alpha^{L}\right) .
$$

Voters have no observations on the opponent's competency; hence

$$
E_{t}^{P}\left[W *\left(\epsilon_{t+1}^{0}\right)\right]=\Omega^{0}=\rho^{2} W *\left(2 \alpha^{H}\right)+2 \rho(1-\rho) W *\left(\alpha^{H}+\alpha^{L}\right)+(1-\rho)^{2} W *\left(2 \alpha^{L}\right) .
$$

Clearly, $\Omega^{H}>\Omega^{\circ}>\Omega^{L}$.

\section{Optimality for Voters and Leaders Under Asymmetric Information}

I now return to the asymmetric information structure summarized in table 1. Although the public cannot directly observe $\alpha_{t}$ until period $t+1$, they can form "beliefs" about $\alpha_{t}$ given their observations on $g_{t}$ and $\tau_{t}$. These beliefs 
can be parameterized as $\hat{\rho}\left(g_{t}, \tau_{t}\right)$, where $\hat{\rho}$ is the probability weight the public attaches to the possibility that $\alpha_{t}=\alpha^{H}$. [Since $\alpha_{t-1}$ will be a fixed, known parameter throughout the next three sections, I abbreviate $\hat{\rho}\left(g_{t}, \tau_{t} ; a_{t-1}\right)$ as $\left.\hat{\rho}(g, \tau).\right]$ The incumbent will be described as a "type $H^{\prime \prime}$ (or "competent type") if $\alpha_{t}=\alpha^{H}$, and a "type L" (or "incompetent type") if $\alpha_{t}=\alpha^{L}$. It is also convenient to define $\epsilon^{H}=\alpha_{t-1}+\alpha^{H}$, and $\epsilon^{L}=\alpha_{t-1}+\alpha^{L}$. We will initially focus our attention on the final election period, $t=T-2$. Clearly, the winner of the T-2 election has no incentive to distort in $T-1$ or $T$. Thus $E_{t}^{P}\left[W\left(\epsilon_{T-1}\right)\right]=E_{t}^{P}\left[W *\left(\epsilon_{T-1}\right)\right]$ if the incumbent wins and similarly for his opponent. By eqs. $(13)-(16)$, voters with priors $\hat{\rho}(g, \tau)$ will set

$$
u=\left\{\begin{array}{l}
1 \text { if } \hat{\rho} \Omega^{H}+(1-\hat{\rho}) \Omega^{L}-\Omega^{0}+q-q^{0} \geqslant 0, \\
0, \text { otherwise. }
\end{array}\right.
$$

The incumbent can infer $\hat{\rho}(g, \tau)$ when formulating his election-year fiscal policy, but he must act before observing $q-q^{0}$ (see again table 1). The incumbent's estimate of his probability of re-election, conditional on his information set, is given by

$$
\begin{aligned}
& E^{I}\left\{u\left[\hat{\rho}(g, \tau), q-q^{0}\right]\right\}=\pi[\hat{\rho}(g, \tau)]= \\
& \quad 1-G\left(\Omega^{0}-\hat{\rho}(g, \tau) \Omega^{H}-[1-\hat{\rho}(g, \tau)] \Omega^{L}\right\},
\end{aligned}
$$

where $G$ is the probability distribution function of $q-q^{0}$. If the incumbent knows $\hat{\rho}(g, \tau)$, he can calculate for any fiscal policy the probability that $q-q^{0}$ will be high enough for him to win. The possibility for signalling arises here because by eq. (6), there is a limit to how much an incumbent would be willing to distort fiscal policy in order to fool the public about his competency type. (As a representative agent, he too cares about the mix of consumption and investment.) 
Using eqs. (3), (4), (6), (11) and (18), one can write an incumbent of type i's maximization problem as:

$$
\max _{g, \tau} z\left[g, \tau, \hat{\rho}(g, \tau), \epsilon^{i}\right]=x^{i} \pi[\hat{\rho}(g, \tau)]+W\left(g, \tau, \epsilon^{i}\right) ; i=L, H,
$$

s.t. to $(10)$, where

$$
x^{i}=\beta\left[X(1+\beta)+\Omega^{i}-\Omega^{\circ}\right], \quad i=L, H .
$$

The first term on the right-hand side of (19) is the incumbent's expected chance of winning, $\pi$, multiplied by his surplus from winning $x^{i}$. Examining eq. (20), we see that this surplus consists of two components: The term $x\left(\beta+\beta^{2}\right)$ captures the (discounted) ego rents for periods $t+1$ and $t+2$, and the term $\beta\left(\Omega^{i}-\Omega^{0}\right)$ is the amount by which the representative agent's expected utility would be higher if the incumbent wins instead of his opponent.

Two features distinguish the objective functions of a competent type and an incompetent type in (19). First, a competent type knows that expected social welfare will be higher if he is re-elected than if his unknown opponent wins. An incompetent knows the opposite to be true. I assume that $x^{L}>0$. 0therwise an incompetent simpiy will not run for re-election, in which case both types are free to pursue their optimal full-information fiscal policy. ${ }^{12}$ The second difference between the two types is that at any given level of $T-g$, a type $H$ is investing $\epsilon^{H}-\epsilon^{L}=a^{H}-a^{L}$ more units into $k_{t+1}$ than a type $L$ is, by eq. (2). By eq. (11), the utility value of this difference is

$$
W\left(g, \tau, \epsilon^{H}\right)-W\left(g, \tau, \epsilon^{L}\right)=\beta\left[V\left(\tau+\epsilon^{H}-g\right)-V\left(\tau+\epsilon^{L}-g\right)\right] .
$$

Since $V^{\prime \prime}<0$, a type $H$ can raise government consumption spending or cut taxes at lower marginal cost than can a type $L$, at any given $(g, T)$. 


\section{Sequential Equilibria}

The interaction between incumbent politicians and rational voters here can be thought of as a multi-dimensional signalling problem, with $g$ and $\tau$ as signals of the incumbent's (contemporaneousiy) unobserved competency.

Multidimensional signalling games have recently been analyzed in the industrial organization literature by Milgrom and Roberts (1986), and by Bagwell and Ramey (1987). In this section, I will follow these authors' general approach for characterizing an equilibrium. First, I consider all sequential equilibria [see Kreps and Wilson (1982)] which are separating. In a separating equilibrium, voters can exactly infer the incumbent's competency shock from his fiscal policy. There turn out to be a multiplicity of separating equilibria but, by using a refinement of sequential equilibrium [sequential elimination of dominated strategies; Moulin (1979) and Milgrom and Roberts (1986)], it is possible to rule out all but one. I then consider pooling equilibria, in which incompetent types might mimic the fiscal policy of competent types. Using a further refinement, due to Cho and Kreps (1987), one can rule out any undominated pooling equilibria. The unique equilibrium which survives both refinements is separating. Competent types set taxes too low and government spending too high before elections, whereas incompetent types pursue their fullinformation policy.

\section{A. Definition of Equilibrium}

For the moment, we will restrict attention to pure strategies. For $i=L, H$, let $\left(g^{i}, \tau^{i}\right)$ describe a strategy for the incumbent leader, and let $u\left[\hat{\rho}(g, \tau), q-q^{0}\right]$ describe a strategy for voters. ${ }^{13}$ Then the pair $\left\{\left(g^{i}, \tau^{i}\right), i=L, H ; u\left[\hat{\rho}(g, \tau), q-q^{0}\right]\right\}$ describes a sequential equilibrium (in pure strategies) if: 
(a) Voters set $v$ according to (17); (b) an incumbent of type $i$ chooses $\left(g^{i}, T^{i}\right) \quad$ to solve his maximization problem (19); and (c) agents ' beliefs are Bayes-consistent:

If $\left(g^{L}, \tau^{L}\right) \neq\left(g^{H}, \tau^{H}\right)$, then $\hat{\rho}\left(g^{L}, \tau^{L}\right)=0, \hat{\rho}\left(g^{H}, \tau^{H}\right)=1$.

If $\left(g^{L}, \tau^{L}\right)=\left(g^{H}, \tau^{H}\right)$, then $\dot{\rho}\left(g^{i}, \tau^{i}\right)=\rho, i=L, H$.

For the remainder of section V, I use the term "equilibrium" as an abbreviation for "sequential equilibrium."

\section{B. Separating Equilibria}

In a separating equilibrium, $\left(g^{L}, \tau^{L}\right) \neq\left(g^{H}, \tau^{H}\right), \hat{\rho}\left(g^{L}, \tau^{L}\right)=0$ and $\hat{\rho}\left(g^{H}, \tau^{H}\right)=1$.

Theorem 1: In any separating equilibrium, $\left(g^{L}, \tau^{L}\right)=\left[g^{*}\left(\epsilon^{L}\right), \tau^{*}\left(\epsilon^{L}\right)\right]$.

Proof: Suppose, in contradiction to the theorem, that $\left(g^{L}, \tau^{L}\right)$ $=\left(\tilde{g}^{L}, \tilde{\tau}^{L}\right) \neq\left[g^{\star}\left(\epsilon^{L}\right), \tau^{\star}\left(\epsilon^{L}\right)\right]$. This would violate optimality condition (19) since for any $\dot{\rho}\left[g^{\star}\left(\epsilon^{L}\right), \tau \star\left(\epsilon^{L}\right)\right]$,

$$
\begin{gathered}
Z\left(g^{*}\left(\epsilon^{L}\right), \tau^{\star}\left(\epsilon^{L}\right), \hat{\rho}\left[g^{\star}\left(\epsilon^{L}\right), \tau^{*}\left(\epsilon^{L}\right)\right], \epsilon^{L}\right)-Z\left(\tilde{g}^{L}, \tilde{\tau}^{L}, 0, \epsilon^{L}\right)>0 . \\
\text { Q.E.D. }
\end{gathered}
$$

In other words, if $\left(\tilde{g}^{L}, \tilde{\tau}^{L}\right)$ were indeed a separating equilibrium fiscal policy for a type L then, by definition, voters must know that he is incompetent, i.e. $\hat{\rho}\left(\tilde{g}^{L}, \tilde{\tau}^{L}\right)=0$. So a type $L$ can only gain by defecting and choosing his full information fiscal policy, $\left[g^{\star}\left(\epsilon^{L}\right), \tau^{\star}\left(\epsilon^{L}\right)\right]$.

To demonstrate the existence of any particular separating equilibrium, it is necessary to specify what voters would believe if they saw a $(g, \tau)$ 
different from $\left(g^{L}, \tau^{L}\right)$ or $\left(g^{H}, \tau^{H}\right)$. Sequential equilibrium (without the refinements I will later apply) places no restrictions whatsoever on these "off-the-equilibrium" path beliefs, except that they must be sufficient to induce the incumbent leader to choose his equilibrium fiscal policy. For the present, the most convenient specification of off-the-equilibrium path beliefs is that $\hat{\rho}(g, \tau)=0 \forall(g, \tau) \neq\left(g^{H}, \tau^{H}\right)$. Given these beliefs, condition (19) is satisfied for a type $L$ if $\left(g^{H}, \tau^{H}\right) \notin A$, where

$$
A=\left\{\left(g^{H}, \tau^{H}\right) \mid Z\left[g^{\star}\left(\epsilon^{L}\right), \tau^{*}\left(\epsilon^{L}\right), 0, \epsilon^{L}\right]-Z\left(g^{H}, \tau^{H}, 1, \epsilon^{L}\right)<0\right\} .
$$

In figure 1 , set $A$ is contained within the dashed ellipse, and point $I$ is $\left[g^{*}\left(\epsilon^{L}\right), \tau^{*}\left(\varepsilon^{L}\right)\right]$. The set $A$ is necessarily convex as drawn, since $W$ is strictly concave in $\tau$ and 9 . A type $L$ would prefer to choose any point within the dashed ellipse instead of choosing point I if by doing so, he could fool the public into thinking that he is a type $H$. Our assumption the $U$ and $V$ obey Inada conditions, together with the assumption that $\lim V(k)=-\infty$, insure that the dashed ellipse lies inside the boundaries $k \rightarrow 0$ $g>0, \tau<\bar{y}, \tau+\epsilon^{L}-g>0$. Point $J$ in figure 1 corresponds to $\left[g^{\star}\left(\epsilon^{H}\right), \tau^{\star}\left(\epsilon^{H}\right)\right]$. Because all goods are normal, point $J$ must lie southeast of point I. Whether point J lies within the dashed ellipse (in which case it cannot be a separating equilibrium strategy for a type $H$ ) depends on a number of factors. It is more likely to be interior the larger $x$ (ego rents), the smaller $\epsilon^{H}-\epsilon^{L}$, and the lower the variance of $q-q^{\circ}$.

By optimality condition (19), another necessary condition for separating equilibrium is that $\left(g^{H}, \tau^{H}\right) \in B$, where

$$
B=\left(\left(g^{H}, \tau^{H}\right) \mid Z\left(g^{H}, \tau^{H}, 1, \epsilon^{H}\right)-Z\left[g^{\star}\left(\varepsilon^{H}\right), \tau^{\star}\left(\varepsilon^{H}\right), 0, \epsilon^{H}\right] \geqslant 0\right\} .
$$

The large solid ellipse in figure 1 contains the convex, compact set $B$. The 
shaded area is $B \cap A^{\prime}$, where $A^{\prime}$ is the complement of $A$. Any point in the shaded region can be a separating equilibrium strategy for a type $H$.

Definition 1: A separating equilibrium is given by $\left(\left(g^{H}, \tau^{H}\right) \in B \cap A^{\prime},\left(g^{L}, \tau^{L}\right)=\left[g \star\left(\epsilon^{L}\right), \tau^{\star}\left(\epsilon^{L}\right)\right]\right\}$.

Theorem 2: $B \cap A^{\prime}$ is a nonempty, compact set.

Proof: Using the definition of $Z$ in (19) and (20), the theorem follows directly from the fact $x^{H}>x^{L}$ and $V^{\prime \prime}<0$. Q.E.D.

\section{c. Undominated Separating Equilibria}

The multiplicity of equilibria in figure 1 can be drastically reduced (to a single point) by placing a very plausible restriction on voters' off-theequilibrium path beliefs. Consider point $E$ in figure 1, for example, and point $D$ which lies along the ray $\overrightarrow{J E}$. Clearly, if $\hat{\rho}=1$ at both $D$ and $E$, a type $H$ would never choose $E$ over $D$. Point $E$ can only obtain as a separating equilibrium if voters think that for some reason, a type $L$ might choose point D. But such beliefs are implausible because a type $L$ would be better off choosing point I than point $D$, no matter what the difference is between $\hat{\rho}$ at $I$ versus $D$. Formally, a point $(\tilde{g}, \tilde{\tau})$ is dominated for type $i, i=L, H$ if

$$
z\left[g^{\star}\left(\epsilon^{i}\right), \tau^{\star}\left(\epsilon^{i}\right), 0, \epsilon^{i}\right]-z\left(\tilde{g}, \tilde{\tau}, 1, \epsilon^{i}\right)>0
$$

In figure 1, any point outside the dashed ellipse is dominated for a type $L$, and any point outside the large solid ellipse is dominated for a type $H$. We shall rule out dominated equilibria by requiring that $\hat{\rho}=1$ at any point such that (24) holds for $L$ but not for $H$, and $\hat{\rho}=0$ if (24) holds for $H$ but not for $L$. The set of points which are dominated for $L$ but not $H$ is precisely $B \cap A^{\prime}$, 
the shaded region in figure 1. Thus, for any $(g, \tau) \in B \cap A^{\prime}, \hat{\rho}=1$. For all (g, T) $€ B \cap A^{\prime}$, we shall assume $\dot{\rho}=0$. In an undominated separating equilibrium, condition (19) will hold if $\left(g^{H}, \tau^{H}\right)$ is chosen to solve

$$
\begin{aligned}
& \max _{g, \tau} W\left(g, T, \epsilon^{H}\right) \\
& \text { s.t. }(10) \text { and }(g, T) \in A^{\prime} .
\end{aligned}
$$

Theorem 3: There exists a unique, undominated separating equilibrium, and in this equilibrium $U_{1}(\bar{y}-\tau, g)=U_{2}(\bar{y}-\tau, g)$.

\section{Proof: See Appendix.}

Note that the condition $U_{1}=U_{2}$, which implicitly defines the curve $T=\phi(g)$, is precisely the same as one of the first-order conditions for the full information optimum, given by eq. (12). Hence $\phi^{\prime}<0$, and $\phi(g)$ passes through points $I$ and $J$ in figure 1 . The undominated equilibrium is given by point $C$ in figure 1 where $g>g^{\star}\left(\epsilon^{H}\right)$ and $\tau<\tau^{\star}\left(\epsilon^{H}\right)$. The second-order conditions are met at point $C$, but not at point $F .^{14}$

Note that in the unique undominated separating equilibrium, there is a political budget cycle (on average). Taxes are suboptimally low at point $C$ and government consumption spending is suboptimally high. Although government investment is too low, signalling is "efficient" in the sense that a reallocation of expenditures between private and government consumption cannot yield voters higher we lfare. ${ }^{15}$

\section{Pooling Equilibria}

Sequential elimination of dominated strategies is not necessarily sufficient to rule at all pooling equilibria. For example, if $\rho$ is large 
enough, then $\left(g^{L}, \tau^{L}\right)=\left(g^{H}, \tau^{H}\right)=\left[g^{*}\left(\epsilon^{H}\right), \tau^{\star}\left(\epsilon^{H}\right)\right] ; \hat{\rho}\left[g^{*}\left(\epsilon^{H}\right), \tau^{*}\left(\epsilon^{H}\right)\right]=\rho$ can be an undominated pooling equilibrium. Here, by applying a further refinement of sequential equilibrium, I show that one can rule out undominated pooling equilibria (in both pure and mixed strategies).

Following Cho and Kreps, an equilibrium $\left\{\left(g^{L}, \tau^{L}\right),\left(g^{H}, \tau^{H}\right)\right\}$ is unintuitive if there exists a point $(\tilde{g}, \tilde{\tau})$ such that

$$
z\left(\tilde{g}, \tilde{\tau}, 1, \epsilon^{H}\right)-Z\left[g^{H}, \tau^{H}, \hat{\rho}\left(g^{H}, \tau^{H}\right), \epsilon^{H}\right]>0,
$$

and

$$
z\left(\tilde{g}, \tilde{\tau}, 1, \epsilon^{L}\right)-Z\left[g^{L}, \tau^{L}, \hat{p}\left(g^{L}, \tau^{L}\right), \epsilon^{L}\right]<0 .
$$

Condition (26) states that a type $H$ would prefer to select $(\tilde{g}, \tilde{\tau})$ over $\left(g^{H}, \tau^{H}\right)$ if, by doing so, he could convince the public of his true type. Condition (27) states that a type $L$ would prefer to select $\left(g^{L}, \tau^{L}\right.$ ) and elicit voters' equilibrium response $\hat{\rho}\left(g^{L}, \tau^{L}\right)$, than to choose $(\tilde{g}, \tilde{\tau})$ even if $\hat{\rho}(\tilde{g}, \tilde{\tau})=1$. An equilibrium is intuitive if it is not unintuitive.

Theorem 4: All pooling equilibria are unintuitive.

\section{Proof: See Appendix.}

One can easily confirm that the unique undominated separating equilibrium is also an intuitive equilibrium. Henceforth, I reserve the term "equilibrium" to refer to the unique, undominated, intuitive, sequential equilibrium.

\section{Multiple Elections}

The extension to the case where there are many elections is straightforward, given the "overlapping generations" MA(1) stochastic structure of the model. We first observe that equilibrium strategies in period T-2 depend on 
$\alpha_{T-3}$, but are otherwise independent of all variables dated T-3 or earlier. Since $k$ and $\alpha$ are observed by voters with a one-period lag, a leader's actions in $T-3$ have no effect on $E_{T-2}^{P}\left(\alpha_{T-3}\right)$, and thus no effect on his chances of reelection in T-2. Therefore, the leader's maximization problem in the offelection year T-3 reduces to the full information problem (11). This argument is readily extended to prove

Theorem 5: For finite $T$ and for any integer $s, 0<s \leqslant T / 2$,

$$
\left[g\left(\epsilon_{T-2 s+1}\right), \tau\left(\epsilon_{T-2 S+1}\right)\right]=\left[g^{\star}\left(\epsilon_{T-2 S+1}\right), T *\left(\epsilon_{T-2 S+1}\right)\right] \text {. }
$$

In off-election years, the incumbent follows his full-information fiscal policy. There is no incentive to distort in a pre-election year because information asymmetries are temporary. Voters are able to monitor the government perfectly with one-period lag.

Given that $W_{T-3}=W_{T-3}^{*}$, the incumbent's problem in the penultimate election year T-4 is exactly the same as in $T-2$, except that we replace $x^{i}$ in eq. (20) with $\tilde{x}^{i}$, where

$$
\text { (20') } \quad \tilde{X}^{i}=\beta\left[X(1+\beta)+\Omega^{i}-\Omega^{0}\right]+X\left(\beta^{3}+\beta^{4}\right)[\rho \pi(1)+(1-\rho) \pi(0)] .
$$

The first term on the RHS of eq. $\left(20^{\prime}\right)$ is the same as in eq. (20). It captures the ego rents the leader would get in $T-3$ and $T-2$ if re-elected in $T-4$, and the expected welfare difference in $T-3$ and $T-4$ for the representative voter. The second, additional, term in (20') captures the ego rents the leader would get in $T-1$ and $T$, if re-elected twice. The term $\rho \pi(1)+$ $(1-p) \pi(0)$ is incumbent's equilibrium expected chance of winning in $T-2$, conditional on winning in T-4. Eq. (20') extends trivially to the case of $n$ 
elections. Obviously, an incumbent will care more about getting re-elected the longer his expected term and the lower his discount rate.

We have considered the case of finite $T$. When $T$ is infinite, there can be trigger-strategy (or "bootstrap") equilibria, as Rogoff and Sibert (1988) have illustrated in a related context. The equilibrium studied here remains an equilibrium for $T$ infinite, but it is also possible to have equilibria in which there is little or no political budget cycle if (a) the leader's rate of time preference is close to one, (b) exogenous uncertainty (the variance of $q$ here) is not too large, and (c) elections are spaced closely together. ${ }^{16}$ since elections are typically spaced many years apart, and since exogenous uncertainty is probably quite high, even the optimal trigger-strategy equilibrium may not be too different from the non-reputational equilibrium I have analyzed here. Certainly the case for focusing on optimal trigger-strategy equilibria is weaker in a political budget cycle context than it is in the context of monetary policy. In setting the nominal money supply, prices, and interest rates, the government and the private sector interact on a continuous basis. 17

\section{Welfare Implications of Political Budget Cycles}

Certainly a major reason for trying to develop a fully-articulated equilibrium model of political budget cycles is to be able to generate wellmotivated empirical predictions. But perhaps the strongest argument for the equilibrium approach here is that it allows one to consider the welfare implications of alternative shocks and of alternative regimes. In this section, I briefly sketch some illustrative examples. 


\section{A. A Constitutional Amendment to Prevent Political Budget Cycles}

A natural question is whether it makes sense to pass a constitutional amendment which prevents the government from undertaking changes in fiscal policy during election years. [Tufte (1978, p. 152) suggests a change in the timing of the Congressional budget cycle.] Consider an amendment whereby the government would have to commit to both $\left(g_{t-1}, \tau_{t-1}\right)$ and $\left(g_{t}, \tau_{t}\right)$ in offelection period $t-1$. If forced to bind himself to $\left(g_{t}, \tau_{t}\right)$ in period $t-1$, it is easy to see that the incumbent leader would always solve

(28) $\max _{g_{t}, \tau_{t}} E_{t-1} W\left(g_{t}, \tau_{t}, \epsilon_{t}\right)=\rho W\left(g_{t}, \tau_{t}, a_{t-1}+a^{H}\right)+(1-\rho) W\left(g_{t}, \tau_{t}, a_{t-1}+a^{L}\right)$. Forcing the incumbent to commit in advance to election-year fiscal policy precludes signalling, and thus eliminates the political budget cycle. There are two costs. First, the public no longer has any way of distinguishing between $H$ and $L$ types when voting. If for simplicity we ignore the $q-q^{0}$ shock, then the mean cost of this lost information is $\rho \beta\left(\Omega^{H}-\Omega^{0}\right)$. The second cost is that the leader is constrained from reacting to period-t information in setting his period-t fiscal policy.

The relative costs and benefits of the constitutional amendment are transparent in two extreme cases. If $x=0$ and there are no ego rents, then in the absence of restrictions the incumbent always sets fiscal policy optimally. In this case, a constitutional amendment makes no sense. More generally, as long as point $C$ lies near point $J$ in figure 1 (and $\rho$ is not too large), the unrestricted signalling equilibrium is to be preferred. At the opposite extreme, as $X \rightarrow \infty$, election-year fiscal distortions are catastrophic whenever $a_{t}=a^{H}$ (Even so, the public tends to vote for him! By the time they go to the polls, election-year fiscal policy is a sunk cost, and they vote 
based only on expected future welfare). In this case a constitutional amendment is the lesser evil. One can also show that the constitutional amendment is always preferred for $\rho$ sufficiently close to one, though I will not go into details. (Note that a type $H$ must signal by the same amount to prove that he is competent when $\rho=.999$ as when $\rho=.0011$.

\section{Risks of a Constitutional Amendment}

The analysis of the preceding subsection, if anything, overstates the efficacy of placing constitutional constraints on election-year fiscal policy. Realistically, the incumbent has a wide array of fiscal actions with which he can signal, and it is probably impossible to constrain him in all dimensions. Here I show that to be welfare improving, a constitutional amendment must be strict enough to prevent a type $H$ from finding any way to use fiscal policy to signal his type. Otherwise, a constitutional amendment can only exacerbate the welfare costs of the political budget cycle. The intuition for this result is simple. In the absence of legal constraints, a competent incumbent will maximize the welfare of a representative agent subject to the incentivecompatibility constraint that his action be one a type $L$ would not choose to imitate [program (25)]. A constitutional amendment, if it does not preclude all separating equilibria, will only have the effect of inducing a competent incumbent to solve (25) subject to an additional constraint. The informal argument I have just presented does not take into account the effects of the constitutional constraint on the incentive-compatibility constraint. The argument is completed below:

Consider a constitutional constraint of the type

$$
\tau=\psi(g), \quad \psi^{\prime}>0
$$


In figure 2 , the bold curve is $\psi(g) . \psi$ is drawn as a continuous, monotically increasing function; e.g., a balanced budget amendment. However, $\psi(g)$ may take on virtually any form. In fact, the main result below would still hold if (29) were an inequality constraint.

Given the constitutional constraint but in the absence of temporary information asymmetries, the incumbent would set $(g, \tau)$ to maximize (11) subject to (29). Denote the solution to this problem as $\left[g^{\star \star}\left(\epsilon^{i}\right), \tau \star \star\left(\epsilon^{i}\right)\right], i=L, H$. The incentive-compatibility conditions for the constitutionally-constrained case, given below, are analogous to (22) and (23)

$$
\begin{aligned}
& Z\left[g^{\star \star}\left(\epsilon^{L}\right), \tau^{\star \star}\left(\epsilon^{L}\right), 0, \epsilon^{L}\right]-Z\left(g^{H}, \tau^{H}, 1, \epsilon^{L}\right)>0, \\
& Z\left(g^{H}, \tau^{H}, 1, \epsilon^{H}\right)-Z\left[g^{\star \star}\left(\epsilon^{H}\right), \tau^{\star \star}\left(\epsilon^{H}\right), 0, \epsilon^{H}\right] \geqslant 0 .
\end{aligned}
$$

In figure 2, the large dashed ellipse represents the set of points $\left(g^{H}, \tau^{H}\right)$ such that $(30)$ holds with equality, and the solid ellipse is the set of points such that (31) holds with equality. A crucial fact is that the smaller dashed ellipse, which corresponds to the dashed ellipse in figure 1 and borders set $A$, must be constained within the larger dashed ellipse, since $Z\left[g^{\star}\left(\epsilon^{L}\right), \tau^{\star}\left(\epsilon^{L}\right), 0, \epsilon^{L}\right]$

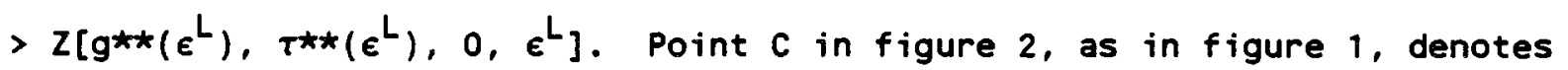
the undominated intuitive equilibrium strategy for a type $H$ in the absence of

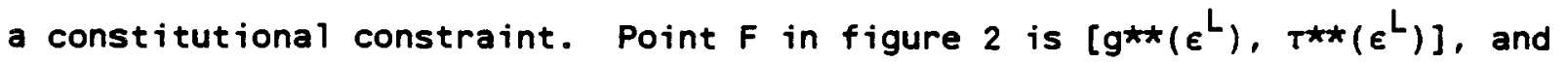
point $G$ is $\left[g^{\star \star}\left(\epsilon^{H}\right), \tau^{\star \star}\left(\epsilon^{H}\right)\right]$; both points lie along the constitutional constraint (29). Point $M$ is the constitutionally-constrained equilibrium level of $\left(g^{H}, \tau^{H}\right),{ }^{18}$ Clearly, the representative voter worse off at $M$ than at $C$. Other efforts to dampen the political budget cycle can also prove counterproductive. For example, it is well known that there can be strategic advantages to having a politically independent central bank. ${ }^{19}$ However, 
contrary to popular belief, central bank independence can exacerbate the welfare costs of political budget cycles. If the number of instruments at the government's disposal is reduced, signalling becomes less efficient.

\section{Self-Financed Campaign Advertising as a Substitute Signal}

Might there exist a less socially-destructive mechanism via which competent incumbents can signal their abilities? In this section, I consider whether a competent type would be willing to spend money out of his own pocket on campaign advertising, instead of signalling solely via fiscal policy. of course, the incumbent has no incentive whatsoever to be honest in his advertisements. He will always claim to be a type $H$. All the public can actually learn from advertising is how much the incumbent is willing to sacrifice from his own consumption in order to be re-elected. Formally, campaign advertising here will correspond to having the incumbent publicly destroy $\sigma$ units of his own personal endowment of the private good. ${ }^{20}$ This dissipative action need not take the form of campaign advertising. Any form of (publicly observable) self-flagellation will do.

With campaign advertising, $W$ in (11) is replaced by

$$
\tilde{W}(g, \tau, \sigma, \epsilon)=U(\bar{y}-\tau-\sigma, g)+\beta V(\tau+\epsilon-g),
$$

where $\sigma \geqslant 0$. Under full information, $\sigma *\left(\epsilon^{i}\right)=0$ for $i=L, H$, and $\left[g^{\star}\left(\epsilon^{i}\right)\right.$, $\left.\tau^{\star}\left(\epsilon^{i}\right)\right]$ are the same as before. Let $z\left(g, \tau, \sigma, \hat{p}, \epsilon^{i}\right)$ be the same as $Z$ in eqs. (19), except with $W$ replaced by $\tilde{w}$, and $\hat{\rho}(g, \tau)$ replaced by $\hat{\rho}(g, \tau, \sigma)$. The conditions for a separating equilibrium are the same as before, except $\tilde{Z}$ replaces $Z$ in (22) and (23). 
Following the same approach as in section V.C, one can show that in an undominated separating equilibrium, a type $H$ sets $\left(g^{H}, T^{H}, \sigma^{H}\right)$ to solve

$$
\max _{g, \tau, \sigma} \tilde{W}\left(g, \tau, \epsilon^{H}\right)
$$

s.t.

$$
g, \sigma,(\tau+\epsilon-g) \geqslant 0 \text {. }
$$

Theorem 6: In an undominated separating equilibrium, $\left(g^{L}, \tau^{L}, \sigma^{L}\right)$ $=\left[g^{\star}\left(\epsilon^{L}\right), \tau^{\star}\left(\epsilon^{L}\right), 0\right], \sigma^{H}=0$, and $\left(g^{H}, \tau^{H}\right)$ solves $(25)$.

\section{Proof: See Appendix.}

A type $H$ incumbent could use advertising to signal his type but by Theorem 6 , he will always prefer to do it with fiscal policy alone. The option of advertising has no effect on the political budget cycle. A type $H$ finds it inefficient to set $\sigma>0$ because he has no comparative advantage in selfadvertising. His marginal cost to raising $\sigma$ one unit is $U_{1}$, the same as for a type L.

\section{E. Reducing Ego-Rents}

If there exists some way to eliminate the leader's ego rents without otherwise distorting his behavior, that would be the first-best policy. Society could pass a constitutional amendment which forces any incumbent running for re-election to pay a fee. This is equivalent to legislating $\sigma \geqslant \bar{\sigma}>0$ in the preceding section. It is easily shown that such a scheme can be welfare improving, though not enough to attain the full-information equilibrium. (If $\bar{\sigma}$ is large enough, only competent types will run for re-election. However, they will then distort fiscal policy towards having low taxes.) As a practical 
matter, incumbents differ greatly in wealth and future earning power, and it may be difficult to properly index $\sigma$.

\section{F. Endogenous Elections}

A very interesting extension of this analysis is to the case where the incumbent has the option of calling a new election after the first period of his term. Such an option is characteristic of the political system in many countries. A call for early elections can itself be a signal, and one can show that a type $\mathrm{H}$ will not need to distort as much during an "early election" as he does during a regular election [see Terrones (1987)]. However, a system with endogenous elections is not necessarily better because political budget distortions tend to occur more frequently. It is not possible to include a thorough analysis of endogenous elections here, but I have mentioned it as an example of the usefulness of this general framework.

\section{Conclusions}

This paper does not fully resurrect the theory of political business cycles. I do, however, present a theory of what I term "political budget cycles." 21 Indeed, it seems that earlier (Keynesian) political business cycle models may have mislead researchers into focusing excessively on tests for cycles in national unemployment and output statistics. Not only do these models rely on questionable Phillips curve foundations, but by restricting attention to national elections, they lead empirical researchers to conduct tests based on only a very limited number of data points. In contrast, the equilibrium theory developed here applies to state and local as well as to national elections. Thus one should uitimately be able to construct an extensive cross-sectional data set with which to test the positive predictions of the model. After extending the analysis to allow for the endogenous timing of 
elections, as discussed in section VII, it will also be possible to study countries which do not have fixed-term elections.

It may seem odd to try to analyze elections and macroeconomic policy cycles within a representative-agent paradigm. But this simplification cuts to the core of the issue, which is that (a) politicians of all stripes enjoy the status they derive from holding high office, and (b) other things equal, all voters prefer to see the government managed efficiently. Any incumbent will try to look competent prior to an election. By employing the representative agent paradigm, one can precisely analyze the welfare implications of a broad number of interventions within an equilibrium framework. However, in future research, it would certainly be desirable to try to integrate the present analys is with heterogeneous-agent models, which have been explored by Alesina (1987) and Ferejohn (1986). 


\section{Appendix}

\section{Proof of Theorem 3}

$$
\begin{aligned}
\Lambda= & U(\bar{y}-\tau, g)+\beta V\left(\tau+\epsilon^{H}-g\right) \\
& +\lambda\left[\kappa_{0}-U(\bar{y}-\tau, g)-\beta V\left(\tau+\epsilon^{L}-g\right)\right],
\end{aligned}
$$

where $\quad k_{0}=x^{L}[\pi(0)-\pi(1)]+W *\left(\epsilon^{L}\right)$. Then the Kuhn-Tucker conditions are

$$
U_{1}-\beta V_{H}^{\prime}-\lambda\left(U_{1}-\beta V_{L}^{\prime}\right) \leqslant 0 \quad(=0 \text { if } \bar{y}-\tau>0) \text {. }
$$

$$
U_{2}-\beta V_{H}^{\prime}-\lambda\left(U_{2}-\beta V_{L}^{\prime}\right) \leqslant 0 \quad(=0 \text { if } g>0) \text {. }
$$

where $\quad V_{i}^{\prime}=V^{\prime}\left(\tau+\epsilon^{i}-g\right)$.

The Inada conditions insure an interior solution, and hence (A1) and (A2) imply

$$
u_{1}(\bar{y}-\tau, g)=U_{2}(\bar{y}-\tau, g) \text {. }
$$

Eq. (A4) is the same as eq. (12) and defines the income expansion path $\tau=\phi(g)$. Since both goods are normal, $\phi^{\prime}<0$, and (A3) and (A4) are satisfied with equality at exactly two points. At point $C$ in figure $1, \beta V_{i}>U_{1}$, $i=H, L$, and $\lambda=\left(U_{1}-\beta V_{H}^{\prime}\right) /\left(U_{1}-\beta V_{L}^{\prime}\right)<1$. At point $F, \beta V_{i}^{\prime}<U_{1}$ and $\lambda>1$. To check the second-order conditions at points $C$ and $F$, form

$$
D=\left|\begin{array}{ccc}
0 & G_{\tau} & G_{g} \\
G_{\tau} & \Lambda_{\tau \tau} & \Lambda_{\tau g} \\
G_{g} & \lambda_{\Lambda \tau} & \Lambda_{g g}
\end{array}\right|
$$


where $G=\kappa_{0}-U(\bar{y}-\tau, g)-\beta V\left(\tau+\epsilon^{L}-g\right)$.

$\left(\bar{D}_{1}\right)=-G_{T}^{2}<0$,

$\left(\bar{D}_{2}\right)=(1-\lambda)\left[2 U_{12}-U_{11}-U_{22}\right]\left(U_{1}-\beta V_{L}^{\prime}\right)^{2} \geqslant 0$ as $\lambda \leqq 1$,

since $2 U_{12}-U_{11}-U_{22}>0$ because $c$ and $g$ are normal goods. Q.E.D.

\section{Proof of Theorem 4}

Suppose $\left(g^{P}, T^{p}\right)$ is any point which is selected with positive probability by both types in a pooling equilibrium. Let $R^{i}(g, \tau) \equiv Z\left(g, \tau, 1, \epsilon^{i}\right)-$ $Z\left[g^{p}, \tau^{p}, \hat{\rho}\left(g^{p}, \tau^{p}\right), \epsilon^{i}\right], i=L, H$. Select the unique pair $[\tilde{g}, \phi(\tilde{g})]$ such that (a) $\phi(\tilde{g})-\tilde{g}<\tau^{\star}\left(\epsilon^{H}\right)-g^{\star}\left(\epsilon^{H}\right)$ and $(b) R^{H}[\tilde{g}, \phi(\tilde{g})]=0$. The existence of this pair is assured by $V^{\prime}(0)=-\infty$. Since $U[\bar{y}-\phi(g), g] \geqslant U\left(\bar{y}-\tau^{p}, g^{p}\right)$ whenever $\phi(g)-g=\tau^{p}-g^{p}$, and since $\pi(1)>\pi(\hat{\rho})$, then by $(b), \phi(\tilde{g})-\tilde{g}<\tau^{p}-g^{p}$. Hence by $V^{\prime \prime}<0, R^{L}[\tilde{g}, \phi(\tilde{g})]<0$. By the continuity of $R^{i}$, there $\exists \delta>0$ such that $R^{H}[\tilde{g}-\delta, \phi(\tilde{g}-\delta)]>0$ and $R^{L}[\tilde{g}-\delta, \phi(\tilde{g}-\delta)]<0$. Q.E.D.

Geometrically, there must always exist some point on $\phi(g)$ sufficiently far southeast of $J$ in figure 1 such that both (26) and (27) hold. 


\section{Proof of Theorem 6}

$$
\begin{aligned}
\Lambda= & U(\bar{y}-\tau-\sigma, g)+\beta V\left(\tau+\epsilon^{H}-g\right) \\
& +\lambda\left[k_{0}-U(\bar{y}-\tau-\sigma, g)-\beta V\left(\tau+\epsilon^{L}-g\right)\right]+\theta \sigma .
\end{aligned}
$$

(A5) $U_{2}-\beta V_{H}^{\prime}=\lambda\left(U_{2}-\beta V_{L}^{\prime}\right)$,

(A6) $\quad-U_{1}+\beta V_{H}^{\prime}=\lambda\left(-U_{1}+\beta V_{L}^{\prime}\right)$,

(A7) $(\lambda-1) U_{1}+\theta \leqslant 0 \quad(=0$ if $\sigma>0)$.

(AB) $K_{0}-U(\bar{y}-\tau-\sigma, g)-\beta V\left(\bar{y}+\tau+\epsilon^{L}-g\right) \geqslant 0 \quad(=0$ if $\lambda>0)$,

(A9) $\sigma \geqslant 0 \quad(=0$ if $\theta>0)$.

Assume in contradiction to the theorem that $\sigma>0$. Then $\theta=0$, (A7) must hold with equality, and hence $\lambda=1$. But then (A5) and (A6) require

$$
V^{\prime}\left(\tau+\epsilon^{H}-g\right)=V^{\prime}\left(\tau+\epsilon^{L}-g\right)
$$

which is impossible. Hence $\sigma=0$ is the only solution, in which case $U_{1}=U_{2}$. The proof that second-order conditions hold at the optimum is similar to the proof of theorem 3 .

Q.E.D. 


\section{REFERENCES}

Alesina, Alberto, "Macroeconomic Policy in a Two-Party System as a Repeated Game," Quarterly Journal of Economics 102 (August 1987), 651-78.

Alesina, Alberto, and Jeffrey D. Sachs, "Political Parties and the Business Cycle in the United States, 1948-1984," Journal of Money, Credit and Banking 19 (1987), forthcoming.

Alt, James E., and K. Alec Chrystal, Political Economics (Sussex: Wheatsheaf Books Ltd., 1983).

Bagwe 11, Kyle, and Garey Ramey, "Advertising and Limit Pricing," mimeo, Stanford University (Apri1 1987).

Beck, Nathanie1, "Elections and the Fed: Is There a Monetary Political Cycle?" American Journal of Political Science 31 (1987), 194-216.

Chappe 11, Henry and William Keech, "Welfare Consequences of a Six-Year Presidental Term Evaluated in the Context of a Model of the U.S. Economy," American Political Science Review 77 (1983), 75-91.

Cho, In-Koo, and David M. Kreps, "Signaling Games and Stable Equilibria," Quarterly Journal of Economics 102 (May 1987), 179-221.

Cukierman, Alex, and Allan H. Meltzer, "A Positive Theory of Discretionary Policy, the Cost of Democratic Government, and the Benefits of a Constitution," Economic Inquiry 24 (July 1986), 367-88.

Fair, Ray C., "The Effect of Economic Events on Votes for President: 1984 Update," NBER Working Paper No. 2222 (April 1987).

Ferejohn, John A., "Incumbent Performance and Electoral Control," Public Choice 50 (1986), 5-25.

Golden, David G. and James M. Poterba, "The Price of Popularity: The PoliticalBusiness Cycle Reexamined," American Journal of Political Science 24 (1980), 696-714.

Lindbeck, Assar, "Stabilization Policy in Open Economies with Endogenous Politicians," Papers and Proceedings of the American Economic Association (May 1976), 1-19.

Haynes, Stephen E. and Joe Stone, "Does the Political Business Cycle Dominate United States' Unemployment and Inflation," in Thomas Willet (ed.) Political Business Cycles: The Political Economy of Money, Inflation and Employment (Pacific Institute: Claremont, CA) forthcoming.

Keech, William, and Carl Simon, "Electoral and Welfare Consequences of Political Manipulation of the Economy, "Journal of Economic Behavior and Organization 6 (1985), 177-202. 
Kreps, David M., and Robert Wilson, "Sequential Equilibria," Econometrica 50 (July 1982), 863-94.

Milgrom, Paul, and John Roberts, "Price and Advertising Signals of Product Quality," Journal of Political Economy 94 (August 1986), 796-821.

Moulin, Hervé, "Dominance Solvable Voting Schemes," Econometrica 47 (November 1979); 1137-51.

Nordhaus, William D., "The Political Business Cycle," Review of Economic Studies 42 (1975), 169-190.

Rogoff, Kenneth, "The Optimal Degree of Commitment to an Intermediate Monetary Target," The Quarterly Journal of Economics 100 (November 1985), 1169-89.

Rogoff, Kenneth, "Reputation, Coordination and Monetary Policy," forthcoming in Robert J. Barro (ed.), Handbook of Modern Business Cycle Theory (John Wiley: New York).

Rogoff, Kenneth, and Anne Sibert, "Elections and Macroeconomic Policy Cycles," Review of Economic Studies 55 (1988), forthcoming.

Terrones, Marco, "Parties, Administrations and Macroeconomic Policy Cycles," mimeo, University of Wisconsin (October 1987).

Tufte, Edward R., Political Control of the Economy (Princeton: Princeton University Press, 1978).

Williams, John T., "Vector Autoregression Modelling of the Macro-Political Economy," paper presented at the American Political Science Association Meetings (1987).

Willett, Thomas D. (ed.), Political Business Cycles: The Political Economy of Money, Inflation and Employment (Pacific Institute: Claremont, CA) for thcoming. 


\section{FOOTNOTES}

* This research has been supported by the National Science Foundation and the Alfred P. Sloan Foundation. Much of the work on this paper was conducted while the author was on leave as a National Fellow at the Hoover Institution. I an grateful to Marco Terrones for helpful comments on an earlier draft.

${ }^{1}$ See, for example, Nordhaus (1975), Tufte (1978), and Golden and Poterba (1980). Recent examples of the extensive empirical literature on "political business cycles" include Alesina and Sachs (1986), Beck (1987), Haynes and Stone (1987), and Williams (1987).

${ }^{2}$ Rogoff and Sibert (1988) show that political budget cycles can be the outcome of an equilibrium signalling process. The model provided in that paper is not sufficiently articulated, however, to analyze the normative issues raised here. Also, the Rogoff-sibert model allows only for unidimensional signalling. The generalization to multidimensional signalling provided here turns out to be critical for analyzing electoral and constitutional reforms.

${ }^{3}$ A number of previous authors have addressed normative aspects of political budget cycles. See Lindbeck (1976), Tufte (1978), Chappell and Keech (1983), Keech and Simon (1985), Cukierman and Meltzer (1986), and Willet (1987). None of these analyses are based on fully-specified equilibrium models, however.

${ }^{4}$ Tufte $(1978, p .149)$ also suggests that political business cycles may be socially beneficial. He argues that the government may tend to distribute income more equitably prior to elections than it does at other times.

${ }^{5}$ The analysis would be similar in most respects if $\epsilon$ entered the production function multiplicatively, either multiplying $g+k$ or $k$ alone. There would be some differences since a change in $\epsilon$ then has price effects as we 11 as income effects, but the welfare results in section VII would be qualitatively unchanged.

${ }^{6}$ If the incumbent can only run for re-election a finite number of times, the model predicts that there will be no political budget cycle in his last term. In Rogoff and sibert (1988), there are two competing political parties instead of individual candidates.

${ }^{7}$ The MA(1) stochastic structure here is consistent with Fair's (1987) finding that for U.S. presidential elections, voters do not take into account the opposition party's economic performance when it was last in power.

$E_{\text {In }}(6)$, the leader cares about his "looks" shock just as much as private citizens do. All the results below would be exactly the same if $n$ did not enter into an agent's utility function during periods he is the leader. Also, an implicit constraint in (6) is that the leader is not legally allowed to tax himself differently from other individuals.

$9 k$ may be thought of as investment in defense, vesting of public pension funds, off-budget loan guarantees and, in general, any type of government expenditure whose effects are observed by the typical voter only with a lag. 
${ }^{10}$ In part because $\tau$ is not the only signal, there always exists a separating equilibrium in the asymmetric information case, even if $\tau$ is constrained to be positive.

${ }^{11}$ That $\left[g^{\star}(\epsilon), \tau^{*}(\epsilon)\right]$ is the unique global maximum follows from the fact that $U$ and $V$ are strictly concave, and the constraint set [governed by eqs. (2) and (9)] is convex.

${ }^{12}$ One can extend the present analysis to allow for a continuum of types. In this case, types $x^{i}<0$ drop out and all types $x^{i} \geqslant 0$ run for re-election. There is still (on average) a political budget cycle, as any incumbent running for re-election has an incentive to pose as a higher type than he actually is.

${ }^{13}$ I am abbreviating $\left(g^{i}, \tau_{t}^{i} ; a_{t-1}\right)$ as $\left(g^{i}, \tau^{i}\right)$.

${ }^{14}$ The level set of $W\left(g, \tau, \epsilon^{H}\right)$ passing through point $C$ has greater curvature than does the level set of $W(g, \tau, \epsilon L)$ passing through $C$, and vis-versa at $F$. The formal proof is in the appendix.

${ }^{15}$ If the ego rents $(X)$ are large enough, the election-year fiscal policy of a type $H$ can be so distortionary that the public would be better off drawing a type $L$. This is true even taking into account that expected post-election social welfare is unambiguously higher under a type $H$. Of course, the public does not re-elect a type $H$ out of masochistic tendencies. By the time they go to the polls, election-period fiscal distortions are a sunk cost, and they vote based only on expected future welfare.

${ }^{16}$ Ferejohn (1986) considers trigger-strategies in a model of voter control over politicians.

${ }^{17}$ See Rogoff (1987) for a survey of reputational models of monetary policy.

${ }^{18}$ There may not exist any fully separating equilibrium under a constitutional constraint. of course, no pure-strategy pooling equilibrium can yield higher welfare than the solution to (28). Here I restrict attention to constitutional constraints which admit at least one separating equilibrium.

${ }^{19}$ See Rogoff (1985).

${ }^{20}$ Milgrom and Roberts (1986) model advertising this way. In the ir model, advertising may be used as a signal even in an undominated equilibrium. In Bagwell and Ramey's (1987) analysis, advertising is used in the undominated equilibrium only if it would have a direct positive effect on demand under full information.

${ }^{21}$ It may be possible to extend the model to generate electoral cycles in employment. In the present model, taxes are lump sum, but suppose instead taxes distort the labor-leisure decision. One might then expect labor supply to rise during election years when tax rates are low, and to fall in offelection years. 
Table 1. The Timing of Events.

\begin{tabular}{|c|c|c|}
\hline $\begin{array}{l}\text { The incumbent } \\
\text { observes } \alpha_{t} \text { and } \\
\text { sets } \tau_{t}, g_{t} \text { ' } \\
\text { and } k_{t+1} \text {. }\end{array}$ & $\begin{array}{l}\text { Voters observe } \\
\tau_{t}, g_{t}, k_{t}, a_{t-1} \\
q_{t}, q_{t}^{0} \text {, and then } \\
\text { vote. }\end{array}$ & $\begin{array}{l}\text { The winner of the period } \\
t \text { election takes office for } \\
\text { two periods. The timing of } \\
\text { events is the same as in } t \\
\text { except there is no } \\
\text { election until } t+2 \text {. }\end{array}$ \\
\hline period $t$ & Election & period $t+1$ \\
\hline
\end{tabular}


F1gure 1

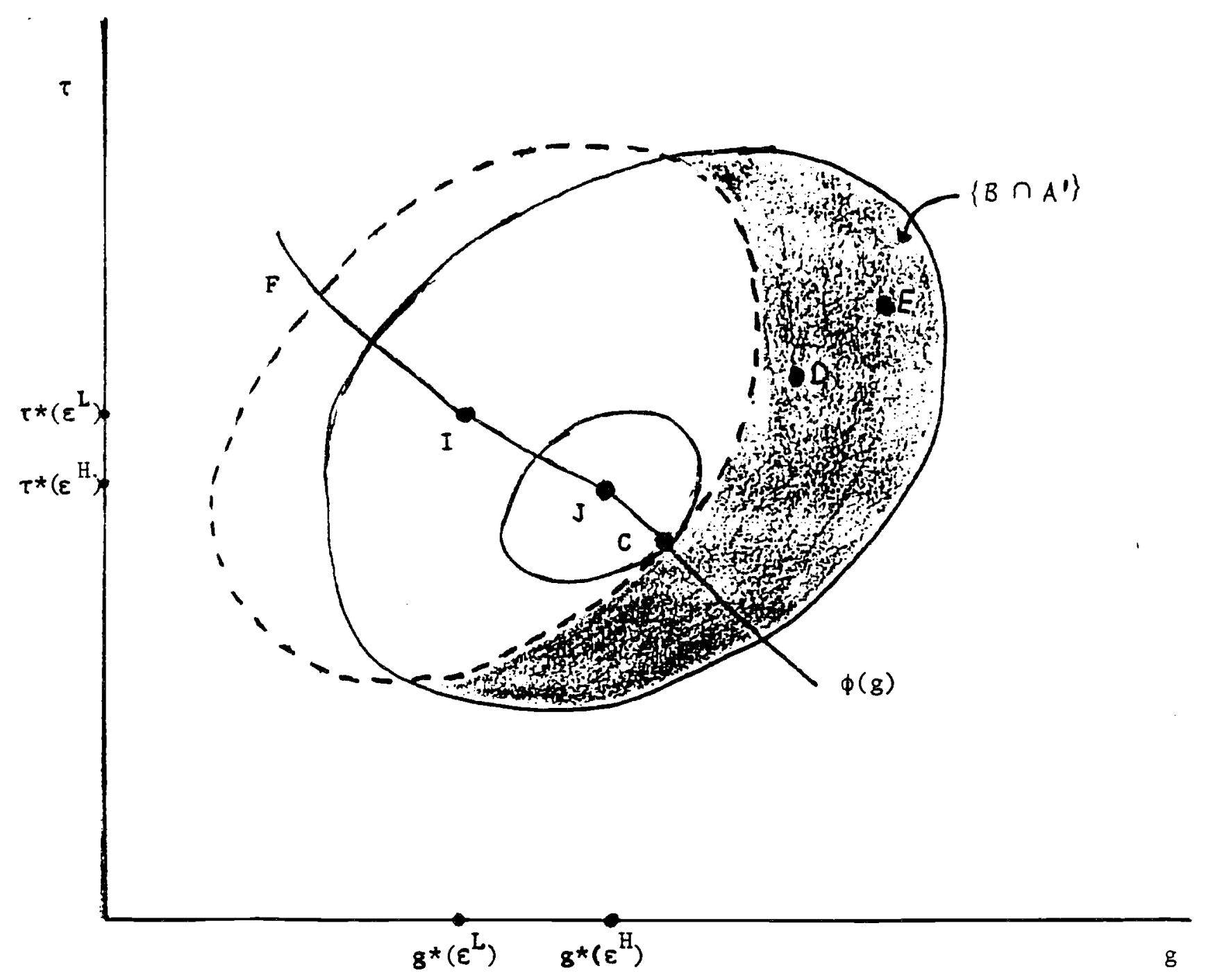


37

Figure 2

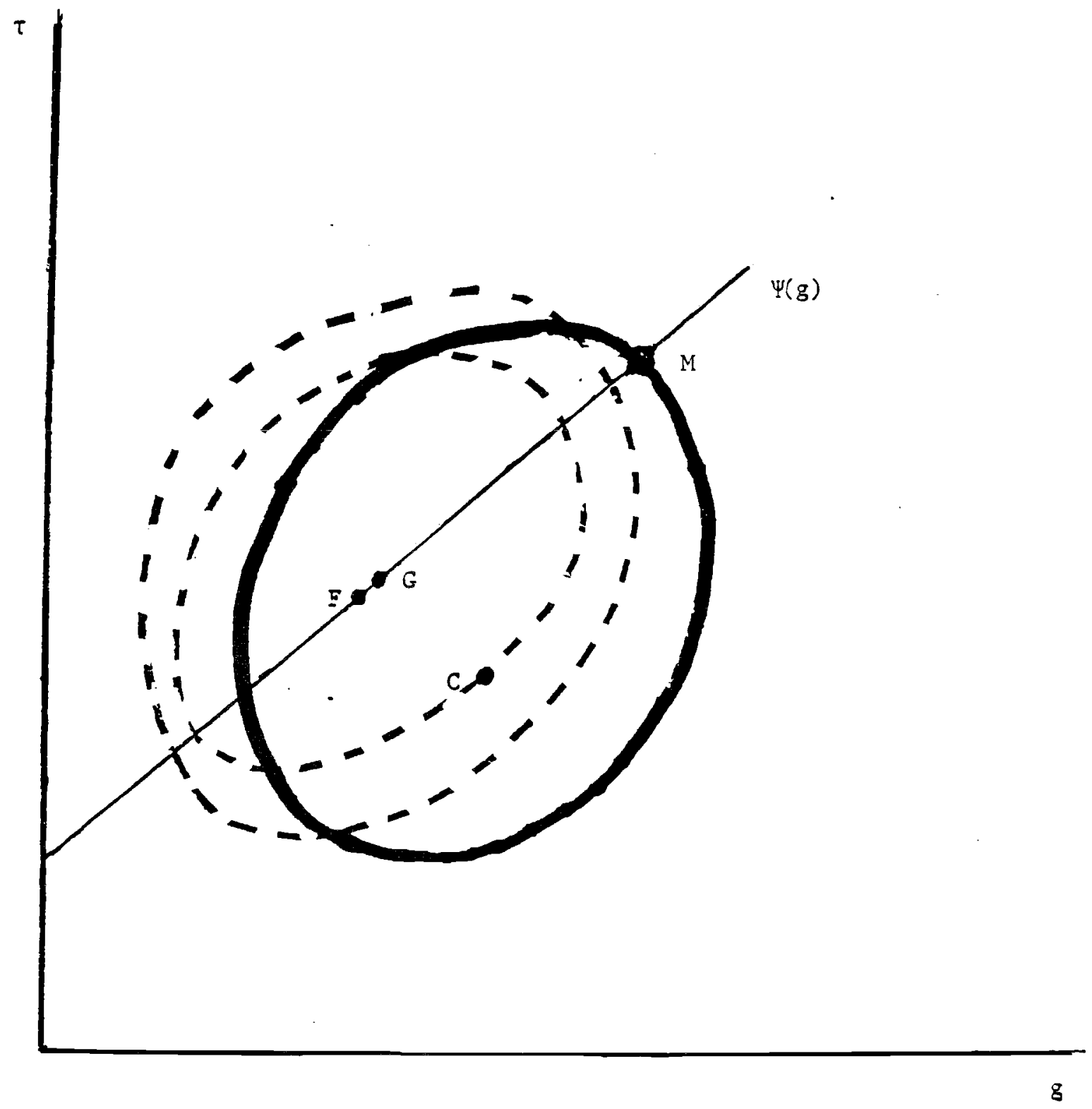

